\title{
Correction to: Improvement of algorithm and prediction precision of an extended Oxley's theoretical model
}

\author{
Liangshan Xiong ${ }^{1} \cdot$ Jie Wang ${ }^{1} \cdot$ Yingye Gan ${ }^{1} \cdot{\text { Bin } \mathrm{Li}^{1}}^{1}$ Ning Fang ${ }^{2}$
}

Published online: 27 August 2019

(C) Springer-Verlag London Ltd., part of Springer Nature 2019

\section{Correction to: The International Journal of Advanced Manufacturing Technology} https://doi.org/10.1007/s00170-014-6361-y

The original version of this article contained a mistake.

The author name "Yinye Gan" should be "Yingye Gan" which is also correctly shown above.

Publisher's note Springer Nature remains neutral with regard to jurisdictional claims in published maps and institutional affiliations.

The online version of the original article can be found at https://doi.org/ 10.1007/s00170-014-6361-y

Liangshan Xiong

liangsx@hust.edu.cn

$\triangle$ Bin Li

libin999@hust.edu.cn

1 School of Mechanical Science and Engineering, Huazhong

University of Science and Technology, Wuhan, Hubei 430074,

People's Republic of China

2 College of Engineering, Utah State University, Logan, UT 84322, USA 